OPEN ACCESS

Edited by:

Ed Maibach,

George Mason University,

United States

Reviewed by:

Bruno Takahashi,

Michigan State University,

United States

Adam Pearson,

Pomona College, United States

*Correspondence:

Nathaniel Geiger nathangeiger@zoho.com

Specialty section:

This article was submitted to Science and Environmental

Communication,

a section of the journal

Frontiers in Communication

Received: 06 August 2018 Accepted: 15 November 2018 Published: 04 December 2018

Citation:

Geiger N and Swim JK (2018) Gendered Impressions of Issue Publics as Predictors of Climate Activism. Front. Commun. 3:54 doi: 10.3389/fcomm.2018.00054

\section{Gendered Impressions of Issue Publics as Predictors of Climate Activism}

\author{
Nathaniel Geiger ${ }^{1 *}$ and Janet Kay Swim ${ }^{2}$ \\ ${ }^{1}$ Indiana University Bloomington, Bloomington, IN, United States, ${ }^{2}$ Psychology, Pennsylvania State University, University \\ Park, PA, United States
}

The present work explores how gendered impressions of issue publics (i. e., those who are well-informed about, and have strong opinions about, a given topic) can predict individuals' interest in engaging in activism either consistent with the issue public's position or diametrically opposed to its position. In two studies (Ns $=286,245$ ) using MTurk samples, we explore the predictors of pro-climate and anti-climate activism based on the impressions of the climate concerned (i.e., an issue public supporting action on climate change; Study 1) and the climate dismissive (i.e., an issue public opposing action on climate change; Study 2). We relied on two complementary theoretical perspectives to make predictions: (a) gender role congruity theory, which suggests that the more perceivers ascribe gendered traits to issue publics that match the perceiver's own gender, the more they will engage in behavior associated with that issue public, and (b) social value of attributes which suggests that various components of femininity and masculinity may be universally valued (i.e., positive aspects of masculinity) or devalued (i.e., negative aspects of femininity) by society regardless of perceivers' own gender. Predictions made by gender role congruity theory were not supported: men, relative to women, did not prefer engaging in activism when they perceived the relevant issue public to be more masculine and women, relative to men, did not tend to prefer engaging in activism when they perceived the relevant issue public to be more feminine. In contrast, results were consistent with social value of attributes predictions suggesting the importance of positive components of masculine impressions of issue publics in promoting activism consistent with the issue public and discouraging activism diametrically opposed to the issue public Yet, results also point to the potential "dark side" of appearing masculine: ascription of negative masculine traits to an issue public was associated with increased willingness to engage in activism diametrically opposed to the issue public and ascribing negative masculine traits to the climate dismissive was associated with, reduced interest in engaging in anti-climate activism. In contrast, ascribing negative feminine traits to an issue public did not uniquely predict interest in engaging in activism either supporting or diametrically opposed to the issue public.

Keywords: stereotypes (social psychology), gender roles and identities, climate change engagement, environmental activism, masculinity-femininity 


\section{GENDERED IMPRESSIONS OF ISSUE PUBLICS AS PREDICTORS OF CLIMATE ACTIVISM}

Activism is one means by which the public can express dissatisfaction with those in positions of power. Periods of public activism can end the status quo and catalyze large-scale societal change, or alternatively, stop proposed large-scale change by demonstrating strong public opposition to these changes. Activism can convey public opinion to and put pressure upon decision-makers (Moyer, 1987; McAdam, 2017) and potentially provide new and useful discourses about a topic to the general public (Swim et al., 2014). Yet, the formation of social movements designed to promote (or discourage) action on issues can sometimes be guided by considerations inconsistent with public opinion on the topic itself. For example, despite opinion polls suggesting overwhelming US public support for action to address climate change in the late 2000s (Maibach et al., 2011) and at least a plurality of support for a cap-and-trade bill to reduce carbon emissions (Mufson and Agiesta, 2009), most publicly visible activism surrounding the cap-and-trade bill at that time opposed the bill-led by the conservative Tea Party movement, which strongly opposed action to address climate change (Dineen, 2011).

In the present work we focus on individuals impressions of issue publics (i.e., those who are highly engaged with, and have strong opinions on, an issue) as predictors of interest in engaging in activism. In the context of climate change (the focus of the present work), the two relevant issue publics are the climate concerned (i.e., members of the public who are most concerned about climate change and support action to address the issue), and the climate dismissive (i.e., members of the public who are least concerned about climate change and oppose action to address the issue). Emerging avenues of research have signaled the relevance of impressions of issue publics in guiding individuals' engagement with issues (Bashir et al., 2013; Geiger, 2018). Here we build off this previous work by explicitly considering the gendered nature of these impressions based on other work suggesting that gender is a core component of impressions of climate change issue publics (Swim and Geiger, 2018), that these gendered impressions can influence decisionmaking (Swim et al., 2018), and more generally, that gender is a core component of how we evaluate others (e.g., Stangor et al., 1992). Thus, these studies suggested that gendered impressions could meaningfully contribute to collective action decisions. Yet, to date, no work that we are aware of has explicitly examined how gendered impressions of issue publics relate to activist behavior. In the present work, we attempt to synthesize and build upon these previous findings by conducting a systematic investigation into how gendered components of impressions about issue publics can promote or discourage activist behavior.

\section{IMPRESSIONS OF ISSUE PUBLIC GROUPS AND ACTIVISM}

Before exploring theoretical frameworks and predictions specifically related to gendered impressions, we first provide a brief general overview of the connection between impressions of issue public groups and interest in engaging in activism. Our reasoning rests in part on the emerging intergroup perspective increasingly used to explain social engagement around the topic of climate change (see Bliuc et al., 2015; Pearson et al., 2016). In this overview section we provide a brief overview of how impressions of specific issue publics could affect individuals' interest in engaging in (a) activism consistent with the issue public and (b) activism diametrically opposed to the issue public.

First, previous research suggests a link between impressions of an issue public and interest in engaging in group-supportive behavior. More specifically, previous research suggests that many hold negative or mixed impressions of activists and the climate concerned (i.e., members of the public who are most concerned about climate change and support action to address the issue), with negativity especially pronounced when considering those who engage in collective action behavior (Bashir et al., 2013; Klas et al., 2018; Swim and Geiger, 2018). Similarly, most hold negative impressions of the climate dismissive (i.e., members of the public who are least concerned about climate change and oppose action to address the issue; Swim and Geiger, 2018). In turn, ascribing negative traits and not positive traits to an issue public or activist group is associated with reduced interest in affiliating with that group and engaging in behavior associated with that group, including activist behaviors associated with the group (Bashir et al., 2013).

Second, we argue that impressions of issue public groups could also influence interest in engaging in activism diametrically opposed to the group. Based on the use of negative political advertising that paints unfavorable impressions of a candidate to promote behaviors that would oppose a candidate (i.e., voting for the competition), it would appear that negative impressions of issue publics might promote collective action diametrically opposed to an issue public's view on climate change. This possibility is further illustrated by calls for anti-climate activism centered around the supposed evils of Democratic politicians Al Gore or Nancy Pelosi (Barker, 2016; Polman, 2018) and calls for pro-climate activism which reference the power of anticlimate vested interests and billionaires in blocking action on climate change (McCarter, 2014). While research has provided mixed support for the efficacy of negative political advertising on certain outcomes (e.g., memory for ads, affect for the target or sponsor of the advertising, voting intention and behavior; Lau et al., 1999), research on collective identity suggest that it may be effective at promoting oppositional collective action. For example, impressions of an issue public group could promote activism opposed to that group as a means of demonstrating to others that one is not a member of the negatively viewed group (see Hogg et al., 1990). We explore and expand upon these concepts in more detail below.

\section{GENDERED IMPRESSIONS OF ISSUE PUBLIC GROUPS}

Research and theory on environmental topics suggest several gender-stereotypical beliefs along which environmental issue publics might be evaluated. On one hand, lay perceptions of 
environmental concerns suggest that such concerns might be seen as feminine which contrast with masculine topics, such as business and technology (Swim et al., 2018). Anecdotes include the anthropomorphism of our planet as "Mother" Earth and actions women have historical taken to nurture and care for people by providing healthy physical environments which frame environmental action as consistent with traditional roles for women (Rome, 2006). Indeed, psychological research supports the notion that environmental issues tend to be perceived by the lay public as feminine (Brough et al., 2016; Swim et al., 2018). On the other hand, gendered impressions of environmental activists may also contain masculine components. In contrast to many other forms of pro-environmental behavior, in which women are more likely than men to engage (Zelezny et al., 2000), research suggests that men may be more likely than women to engage in environmental activism (Mohai, 1992). This may reflect stereotypes indicating that environmental activists, and activists more generally, possess stereotypically masculine traits, such as bravery and arrogance (Bashir et al., 2013; Swim and Geiger, 2018).

Below, we consider two complementary theoretical perspectives on the potential effects of gendered impressions on perceivers' interest in engaging. The first perspective, which draws from gender role congruity theory (Eagly, 1987; Eagly et al., 2000; Diekman and Eagly, 2008), suggests that individuals would be drawn to activism if their gendered impressions of activists matches their own gender. The second perspective, takes a broader societal perspective examining how masculine and feminine gender roles are valued in society. This perspective suggests that the social value of masculinity and femininity might influence both women's and men's activism preferences.

\section{Gender Role Congruity Theory}

Gendered impressions of issue publics may impact individuals' interest in engaging in activism based on whether their perception of the gendered nature of an issue public matches the individual's own gender. Gender role congruity theory (Eagly, 1987; Eagly et al., 2000; Diekman and Eagly, 2008) argues that gender stereotypes derive from societal division of labor and these stereotypes continue to perpetuate this division of labor. The stereotypes set up external expectations for women's and men's behavior with associated social rewards and punishments for conforming to or diverging from the expectations, respectively. These expectations can also be internalized and serve to self-regulate behaviors. For example, many women show reduced motivation in STEM (Science, Technology, Engineering, and Mathematics) disciplines due to the perception that those who are successful in these fields possess masculine rather than feminine traits (London et al., 2011). In contrast, the "reverse gender gap" in the classroom, where boys tend to underperform in grade school, can be explained in part by the perception of organization and dedication to school work as "feminine" (Elmore and Oyserman, 2012). Thus, gender stereotypes associated with roles, and presumably people who occupy the roles, can lead to gender matching where both women and men prefer engaging in behaviors perceived to be consistent with their gender and, correspondingly, men and women hesitate engaging in behavior when they view the behavior as inconsistent with their gender.

Gender role congruity theory suggests preferences for gender matching could influence women's and men's activism preferences. If climate change activism and activists are seen as feminine, women may be encouraged and men may be discouraged from engaging in activism. In contrast, if climate change activists are seen as masculine, men may be encouraged and women discouraged from engaging in activism. Based on the logic derived from gender role theory, we make the following hypotheses:

Hypothesis 1: There will be an interaction between gender and perceived masculine traits, such that women (relative to men) will be less likely to engage in activism supporting a given position when they perceive the issue public supportive of that position to have greater masculine traits.

Hypothesis 2: There will be an interaction between gender and perceived feminine traits, such that men (relative to women) will be less likely to engage in activism supporting a given position when they perceive the issue public supportive of that position to have greater feminine traits.

\section{Social Value of Gendered Attributes}

In contrast to gender role theory, other theory and research suggests that gendered impressions of groups along a given dimension could have fairly similar effects on interest in engaging in activism for both women and men. Gender stereotypes have been argued to represent both the roles and status that women and men have in society (Eagly and Steffen, 1984; Diekman and Eagly, 2000). Masculine stereotypes are argued to reflect the tendency for men to occupy high status and powerful groups, such as occupying leadership roles, and as a result these stereotypes are associated with a cluster of desirable attributes including agency, efficacy and respect (Deaux and Lafrance, 1998; Wojciszke et al., 2009). Thus, perceiving those who engage in a given behavior to possess greater levels of these socially valued masculine traits could motivate both women and men to engage in that behavior. Feminine traits are argued to reflect communal roles in service of others and are associated with warmth, caring for others, and being liked (Deaux and Lafrance, 1998; Abele and Wojciszke, 2007; Wojciszke et al., 2009). Thus, perceiving those who engage in a given behavior to possess greater levels of these socially valued feminine traits could also motivate both women and men to engage in that behavior.

An additional consideration is that the social value of masculine and feminine traits may be dependent upon differences among masculine and feminine traits that suggest that some masculine and feminine traits are more socially desirable than other masculine and feminine traits. Research on gender stereotypes indicates that a full set of gendered impressions can best be derived by considering (a) positive masculine, (b) negative masculine, (c) positive feminine, and (d) negative feminine traits (Spence and Helmreich, 1979; Diekman and Eagly, 2000). Recent work adds nuance and clarity 
to these predictions by considering the predictive power gained by separating gendered impressions into positive and negative components (Swim and Geiger, 2018; Swim et al., 2018). This work reveals that negative masculine traits are more likely than positive masculine traits to be ascribed to the climate dismissive, while positive masculine and negative feminine traits are equally likely to be ascribed to the climate concerned. Additionally, the ascription of negative masculine traits to the climate dismissive decreases the extent to which women and men identify with the group whereas the ascription of negative feminine traits decreases the extent to which men, but not women, identify with the climate concerned (Swim, under review).

Here we adopt a framework which considers all four types of these gendered traits in an effort to examine which components of gendered impressions could best explain interest in engaging in activist behavior. Based on our review of the effects of impressions of issue publics on collective action noted above, we also consider whether issue public group impressions could influence interest in engaging in activism which is (a) consistent with the relevant issue public's opinion position and (b) diametrically opposed to the relevant issue public's opinion position.

\section{Masculine Trait Impressions and Activism}

The impact of masculine trait impressions of issue public groups on interest in engaging in activism may depend on the valence of the masculine traits. As we explain below, past research points to clearer predictions for associations between positive masculine trait impressions and interest in engaging in activism than negative masculine trait impressions and interest in engaging in activism.

Positive masculine traits associated with an issue public could encourage interest in engaging in climate change activism both because the positive nature of the traits makes them socially desirable and because the masculine nature of the traits associates them with agency, respect, and efficacy (Wojciszke et al., 2009). Positive masculine traits could promote a desire to engage with the group as a means of enhancing one's own status through building one's identity as a member of a respected group (Klandermans, 2008; Masson and Fritsche, 2014) because the agency and respect accrued to the group makes engagement with the group seem appealing, or because one might expect to also be perceived in that positive light if one were to engage in a similar behavior [see (Geiger and Swim, 2016)]. In addition, because engaging in activism diametrically opposed to an issue public group can socially signal that one is not part of that group, then perceiving that a group is high in positive masculine traits (and therefore socially desirable) may reduce interest in engaging in activism opposed to a group. Based on this logic, we make the following hypothesis:

Hypothesis $3 a$ and 3b: Ascription of positive masculine traits to an issue public will be associated with (a) greater interest in engaging in activism consistent with that issue public's position and (b) lesser interest in engaging in activism diametrically opposed to that issue public's position.
In contrast, we propose competing predictions for the effects of negative masculine impressions of the issue public (e.g., arrogance and aggression) on interest in engaging in activist behaviors based upon one set of predictions derived from the lack of social desirability of the traits and a second set based upon the agency associated with masculinity. First, the negativity of these impressions suggests that they may be viewed as undesirable traits and people may be motivated to avoid affiliating with those who hold these traits (Bashir et al., 2013). The negativity of these traits could also motivate people to engage in activism diametrically opposed to the group goals, not only potentially to socially distance oneself from the group (Hogg et al., 1990) but also potentially due to a reactance effect (Cottrell and Neuberg, 2005; Miron and Brehm, 2006; Böhm et al., 2016), whereby the perceived aggressive characteristics of the group threatens the perceiver's freedom and opposing action is taken to reassert one's freedom. Second, and in contrast, people may be drawn to those perceived to hold these negative masculine traits because they are associated with agency, power, and status (Diekman and Eagly, 2000). This is consistent with the idea that negative masculine traits can be desirable because they convey an image of being "bad but bold" (Glick et al., 2004). Based on the presence of these competing possibilities, we do not make a directional prediction about relations between perceptions of negative masculine traits and either (a) group-consistent activism or (b) group-inconsistent activism.

\section{Feminine Trait Impressions And Activism}

As with masculine trait impressions, the impact of feminine trait impressions of issue public groups on interest in engaging in activism may depend on the valence of the feminine impression. As we explain below, we develop more clear predictions for associations between negative feminine trait impressions and interest in engaging in activism than we do for positive feminine trait impressions and interest in engaging activism.

Positive feminine traits impressions could promote engaging in activism consistent with the issue public group due to both the social desirability associated with positive traits and because the caring, warmth and liking associated with these traits may increase the desire to affiliate with the target group. These associations could also promote a desire to engage with the group and engage in group-consistent activism, perhaps due in part to people's increasing support for ideas when they believe that a person proposing the idea cares about the average person (Geiger, 2018). In contrast, however, femininity may not be seen as desirable because feminine traits are derived from care-taking societal roles which are low in power and status (Diekman and Eagly, 2000; Eagly et al., 2000). In turn, these expectations of low power and status could discourage people from engaging in activism related to groups perceived to have positive feminine traits or encourage them to engage in activism diametrically opposed to these groups. Based on the presence of these competing possibilities, we do not make directional predictions about relations between perceptions of positive feminine traits and either (a) group-consistent activism or (b) group-inconsistent activism. 
In contrast, negative feminine traits, such as being whiny or complaining, may be viewed as unambiguously undesirable traits. As with positive feminine traits, negative feminine traits are argued to be derived from women occupying roles that low in power and status. In contrast to positive feminine traits, however, it has been suggested negative feminine traits (e.g., being a complainer) tend to be attributed to individuals in these roles who use low-power tactics to exert subversive societal influence (Diekman and Eagly, 2000). Thus, unlike positive feminine traits, these negative feminine traits are not associated with desirable attributes, such as warmth and likeability and are unambiguously undesirable. When individuals perceive groups to have negative feminine traits, they may attempt to socially distance themselves from the group, perhaps in part to prevent stigma by association (Pryor et al., 2012). Individuals may not only avoid engaging in group-consistent activist behaviors when they perceive the issue public group to have negative feminine traits, but may also further distance themselves from the group by engaging in groupinconsistent activist behaviors. Thus, we make the following hypotheses:

Hypothesis $4 a$ and 4b: Ascription of negative feminine traits to an issue public will be associated with (a) lesser interest in engaging in activism consistent with that issue public's position and (b) greater interest in engaging in activism diametrically opposed to that issue public's position.

\section{PRESENT RESEARCH}

Across two studies we test the associations between perceptions of traits associated with climate change issue public groups (i.e., the climate concerned and climate dismissive) and interest in engaging in pro-climate and anti-climate activism. Study 1 assesses participants' stereotypes about the climate concerned. Study 2 assesses participants' stereotypes about the climate dismissive. Thus, in Study 1, pro-climate activism is consistent with the climate concerned's views and anti-climate activism is diametrically opposed to their views and therefore inconsistent with their views. In contrast, in Study 2, anti-climate activism is consistent with the climate dismissive's views and pro-climate activism is diametrically opposed and therefore with their views. Consistent with most other work assessing the relations between multiple interrelated predictors and an outcome, we employ multiple regression techniques (rather than examining zeroorder correlations) to examine the unique predictive power of each predictor and account for potential confounds.

\section{STUDY 1: PERCEPTIONS OF THE CLIMATE CONCERNED}

The purpose of Study 1 was to examine whether impressions of the climate concerned in terms of positive and negative masculine and feminine stereotypes might help explain interest in engaging in pro-climate (i.e., group-consistent) and anticlimate (i.e., group inconsistent) activism.

\section{METHODS}

\section{Participants}

Three hundred thirteen participants were recruited in late January and early February of 2015 from MTURK (Mechanical Turk) and paid $\$ .50$ for their completion of the survey. Twentyseven participants were excluded for not completing a question about gender (2), not providing trait ratings (1), failing an instructional check where they were asked to provide a specific response (none of the above) to a question where they were asked to indicate which of eight emotions reflected their current emotional state (4), completing in $<1 / 2$ the median completion time (18), and/or completing in $>3 \times$ the median completion time (4). The final sample consisted of 286 participants: 131 (46\%) women and 155 (54\%) men. Ages ranged from 19 to 72 (median $=35$ ). Most participants were White/Caucasian $(81 \%)$. The sample was somewhat more educated than the general public: $53 \%$ of participants had a 4 -years college degree. About half of participants identified as politically liberal $(11 \%$ very liberal and 39\% liberal), followed by moderate (30\%) and about one-fifth as politically conservative ( $18 \%$ conservative, $3 \%$ very conservative). Participants indicated their concern about climate change using a single-item measure validated in Swim and Geiger (2017). Similar to the general population (Maibach et al., 2011; Leiserowitz et al., 2015; Swim and Geiger, 2017), most participants were at least somewhat concerned about climate change: $23 \%$ self-identified as Alarmed, $40 \%$ as Concerned, $20 \%$ as Cautious, $5 \%$ as Disengaged, $8 \%$ as Doubtful, and $4 \%$ as Dismissive.

\section{Procedure}

Participants were told that the purpose of the study was related to using mnemonics to improve memory in conversations about controversial topics and were asked to use a mnemonic tool to memorize quotes paired with the names of people alleged to have said the quote. In reality, the quotes were used to create an image of those who are Alarmed about climate change and the memory task was to assure that they read the quotes. ${ }^{1}$ The quotes reflect the belief that climate change was a problem and in need of immediate action (see Appendix). Following their use of the mnemonic tool and associated memory task, participants completed dependent measures, the instruction attention check question (see Participants section above), and demographic questions.

\section{Measures}

\section{Concern About Climate Change}

Because individuals' climate change concern is associated with the extent to which they view activists as possessing positive and negative traits (Swim and Geiger, 2018), we control for

\footnotetext{
${ }^{1}$ Participants were randomly assigned different names of the commenters to reflect either a) all female or b) all male names or c) a mixture of names for a different purpose. Results presented here did not change when we included this variable in the analyses, suggesting that ascription of gendered traits to the climate concerned is not primarily based upon the actual gender of the individuals but rather on the manner in which their actions align with societal expectations of gendered traits. This is consistent with previous theory on gendered traits and popular writing about gendered traits (e.g., Bump, 2013).
} 
this variable in analyses. Participants completed the single-item self-categorization measure of climate change concern developed by Swim and Geiger (2017) by selecting the group that best described their opinions about climate change (Very Concerned, Concerned, Cautious, Disengaged, Doubtful, or Non-believer). Similar to previous work, responses were treated as a continuous measure on a 1 (Non-believer) to 6 (Very Concerned) scale $(M=$ 4.55 , s.d. $=1.31)^{2}$

\section{Political Ideology}

As noted above, participants completed a single-item measure indicating their political ideology on an -2 to +2 scale ranging from very liberal to very conservative and the midpoint indicating "moderate" $(M=-0.37$, s.d. $=0.98)$.

\section{Stereotypes About Climate Concerned}

Based on previous work (Swim and Geiger, 2018), participants used a five-point scale $(0=$ "not at all" to $4=$ "very much") to rate how much they anticipated that a person who was "very concerned about climate change" would possess 12 different traits. The 12 traits represented negative and positive gendered traits (positive masculine traits: courageous, adventurous, standsup under pressure, $\alpha=0.80$; negative masculine traits: aggressive, dictatorial, arrogant. $\alpha=0.78$; positive feminine traits, nurturing, gentle, sympathetic, $\alpha=0.80$; negative feminine traits: nagging, whiny, complaining, Cronbach $\alpha=0.88$ ). Consistent with previous work (Swim and Geiger, 2018) which developed these four categories, model comparisons using confirmatory factor analyses supported this four-factor structure over two-factor structures (negative vs. positive or masculine vs. feminine) and over a single-factor structure.

\section{Interest in Climate Change Activism}

Respondents were asked to indicate their interest in engaging in three forms of pro-climate activism: read blogs by those concerned about climate change, attend a public meeting or presentation about supporting a climate change policy, join a group marching for climate change activism in their state capital (seven-point scale, "very unlikely" (-3) to "very likely" (3); $M$ $=-0.58$, s.d. $=1.68, \alpha=0.82$ ). Using a parallel set of three items, participants also indicated their interest in engaging in three forms of anti-climate activism (e.g., read blogs by those skeptical about climate change, etc.; $M=-1.83$, s.d. $=1.10, \alpha$ $=0.64){ }^{3}$ Across both outcome variables, floor effects occurred due to a substantial minority of participants selecting strongly

\footnotetext{
${ }^{2}$ We also assessed participants' identification with the climate concerned for exploratory purposes. This measure was correlated with participants climate change concern at $r=0.73$, and models substituting this variable for participants climate change concern yielded similar results to those reported below. We tested possible interactions between participants' identification with the climate concerned and trait ascriptions to the climate concerned on pro- and anti-climate activism and found no significant interactions at the $p=0.05$ level.

${ }^{3}$ Participants also rated the extent to which they would work with groups that either reduced or stop the reduction of their communities' contribution to climate change. However, the latter item was positively correlated with pro-climate activism despite the fact that it was intended as an anti-climate activism item; potentially because of the double negative. So, we did not include these items in our measure of willingness to engage in climate change activism.
}

disagree (i.e., -3) on all scale items. Employing ordinary least squares (OLS) regression when there are floor effects in an outcome variable can result in overestimation of standard errors and misestimation of regression parameters (Zhu and Gonzalez, 2017), however, it is not possible to fully address this issue using data transformation among variables that have floor effects. Thus, following recommendations and analysis techniques that have been employed with similar patterns in previous datasets (Zhu and Gonzalez, 2017) we treated the two outcome measures as leftcensored and employed Tobit regression (Tobin, 1958; Breen, 1996) for analyses, which is considered appropriate for censored data (Zhu and Gonzalez, 2017). The technique operates based on the assumption that there is an underlying normally distributed latent variable of interest in engaging in activism, and that many participants on the lower end of this scale, despite differing scores on the underlying latent construct, will score a -3 on the measured variable due to the fact that this is the lowest possible score.

\section{RESULTS}

A table of zero-order correlations between all measures is shown in Table 1.

We conducted regression analyses to examine the predictors of a) pro-climate activism and b) anti-climate activism. With each of these two outcome variables, we began by regressing the outcome measure upon political ideology, climate change concern, the opposite form of activism (to control for the general tendency of low interest in engaging in any sort of activism) and gender in Step 1. In Step 2, we added in main effects of the four types of trait impressions (positive masculine, negative masculine, positive feminine and negative feminine). In Step 3, interactions between each of the types of trait impressions and gender were added. Below, we describe results in the text related to a) testing specific hypotheses and b) statistically significant effects that were not hypothesized. In the text, we include standardized betas (in addition to unstandardized betas) in order to assess the effect size of each relation which is described. For the full results, see Tables 2, 3 .

\section{Gender Role Congruity Predictions}

We first examined the predictions made by gender role theory by examining whether participants would report greater interest in engaging in pro-climate activism when they associated the climate concerned with more traits of the participant's own gender (i.e., Hypothesis 1), and lesser interest in engaging in proclimate activism when they associated the climate concerned with more traits of the other gender (i.e., Hypothesis 2). Hypotheses 1 and 2 predicted inverse patterns would occur when predicting anti-climate activism.

Hypotheses 1 and 2 were not supported: there were no interactions between any trait and participants' own gender on interest in engaging in either pro-climate or anti-climate activism, ps $>0.49$, suggesting that the relationships between the trait impressions and interest in engaging in pro- and anticlimate activism were similar for female and male participants. 
TABLE 1 | Means, standard deviations, and correlations with confidence intervals for measures used in Study 1.

\begin{tabular}{|c|c|c|c|c|c|c|c|c|c|c|c|}
\hline Variable & $M$ & $S D$ & 1 & 2 & 3 & 4 & 5 & 6 & 7 & 8 & 9 \\
\hline $\begin{array}{l}\text { 1. Concern about } \\
\text { climate change }\end{array}$ & 4.55 & 1.31 & & & & & & & & & \\
\hline 3. Age & 37.74 & 12.26 & $\begin{array}{c}-0.11[-0.22 \\
0.01]\end{array}$ & $\begin{array}{c}0.18^{\star \star} \\
{[0.07,0.29]}\end{array}$ & & & & & & & \\
\hline $\begin{array}{l}\text { 5. Positive Masculine } \\
\text { Impressions }\end{array}$ & 2.12 & 0.91 & $\begin{array}{l}0.32^{* \star}[0.21 \\
\quad 0.42]\end{array}$ & $\begin{array}{l}-0.16^{\star \star} \\
{[-0.27} \\
-0.05]\end{array}$ & $\begin{array}{c}0.01 \\
{[-0.11,0.12]}\end{array}$ & $\begin{array}{c}0.14^{\star} \\
{[0.02,0.25]}\end{array}$ & & & & & \\
\hline $\begin{array}{l}\text { 6. Negative Masculine } \\
\text { Impressions }\end{array}$ & 1.57 & 1.01 & $\begin{array}{c}-0.52^{\star \star} \\
{[-0.60,-0.43]}\end{array}$ & $\begin{array}{c}0.39^{\star \star} \\
{[0.28,0.48]}\end{array}$ & $\begin{array}{c}0.06 \\
{[-0.06,0.18]}\end{array}$ & $\begin{array}{l}-0.13^{\star} \\
{[-0.25} \\
-0.02]\end{array}$ & $\begin{array}{c}0.02 \\
{[-0.09,0.14]}\end{array}$ & & & & \\
\hline $\begin{array}{l}\text { 8. Negative Feminine } \\
\text { Impressions }\end{array}$ & 1.65 & 1.13 & $\begin{array}{c}-0.53^{\star \star} \\
{[-0.61,-0.44]}\end{array}$ & $\begin{array}{c}0.39^{\star \star} \\
{[0.29,0.48]}\end{array}$ & $\begin{array}{c}0.02 \\
{[-0.10,0.13]}\end{array}$ & $\begin{array}{l}-0.22^{\star \star} \\
{[-0.33} \\
-0.11]\end{array}$ & $\begin{array}{l}-0.20^{\star \star} \\
{[-0.31} \\
-0.09]\end{array}$ & $\begin{array}{c}0.74^{\star \star} \\
{[0.68,0.79]}\end{array}$ & $\begin{array}{l}-0.25^{\star \star} \\
{[-0.36} \\
-0.14]\end{array}$ & & \\
\hline 9. Pro-Climate Activism & -0.58 & 1.68 & $\begin{array}{c}0.57^{\star \star} \\
{[0.48,0.64]}\end{array}$ & $\begin{array}{l}-0.41^{\star \star} \\
{[-0.50} \\
-0.30]\end{array}$ & $\begin{array}{l}-0.19^{\star \star} \\
{[-0.30} \\
-0.07]\end{array}$ & $\begin{array}{c}0.03 \\
{[-0.09,0.14]}\end{array}$ & $\begin{array}{c}0.32^{\star \star} \\
{[0.21,0.42]}\end{array}$ & $\begin{array}{l}-0.33^{\star \star} \\
{[-0.43} \\
-0.22]\end{array}$ & $\begin{array}{c}0.33^{* \star} \\
{[0.22,0.43]}\end{array}$ & $\begin{array}{l}-0.39^{\star \star} \\
{[-0.48} \\
-0.28]\end{array}$ & \\
\hline $\begin{array}{l}\text { 10. Anti-Climate } \\
\text { Activism }\end{array}$ & -1.83 & 1.10 & $\begin{array}{c}-0.34^{\star \star} \\
{[-0.44,-0.23]}\end{array}$ & $\begin{array}{c}0.21^{\star \star} \\
{[0.10,0.32]}\end{array}$ & $\begin{array}{c}0.03 \\
{[-0.09,0.14]}\end{array}$ & $\begin{array}{l}-0.13^{\star} \\
{[-0.24} \\
-0.01]\end{array}$ & $\begin{array}{c}-0.03 \\
{[-0.14,0.09]}\end{array}$ & $\begin{array}{c}0.33^{\star \star} \\
{[0.23,0.43]}\end{array}$ & $\begin{array}{c}-0.08 \\
{[-0.20,0.03]}\end{array}$ & $\begin{array}{c}0.26^{\star \star} \\
{[0.15,0.36]}\end{array}$ & $\begin{array}{c}0.02[-0.10 \\
0.14]\end{array}$ \\
\hline
\end{tabular}

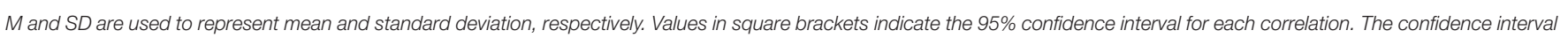
is a plausible range of population correlations that could have caused the sample correlation (Cumming, 2014). ${ }^{*}$ indicates $p<0.05$. ${ }^{\star *}$ indicates $p<0.01$.

\section{General Effects of Gendered Trait Impressions}

As anticipated (Hypothesis 3a), positive masculine traits of the climate concerned uniquely predicted interest in engaging in proclimate activism, $b=0.27$ ( $\beta=0.15), S E=0.12, p=0.03$. In contrast, Hypothesis $4 \mathrm{a}$ was not supported: negative feminine traits did not uniquely predict interest in engaging in pro-climate activism, $b=-0.16(\beta=-0.11), S E=0.12, p=0.18$.

We next conducted a regression analysis to examine the predictors of anti-climate action. The regression was analogous to the regression conducted in the above paragraph. Examining the predictors of anti-climate activism, neither Hypothesis $3 \mathrm{~b}$ or $4 \mathrm{~b}$ were supported: interest in engaging in anti-climate activism was not uniquely predicted by either perceptions of positive masculine traits of the climate concerned, $b=0.00(\beta=0.00), S E$ $=0.10, p=0.98$ or perceptions of negative feminine traits of the climate concerned, $b=-0.01(\beta=-0.01), S E=0.10, p=0.93$. In contrast, negative masculine traits of the climate concerned was uniquely positively related to interest in engaging in anti-climate activism, $b=0.31(\beta=0.29), S E=0.12, p=0.007$.

\section{DISCUSSION}

Study 1 results were inconsistent with predictions made by gender role congruity theory. Specifically, contrary to the predictions of the theory, gendered trait impressions of the climate concerned did not exert gender-specific impacts on women or men's interest in engaging in pro-climate or anticlimate activist behavior.

In contrast, we found informative results that were partly consistent with predictions based on the social value of gendered attributes. Results indicated that consistent with predictions (Hypothesis 3a), ascription of positive masculine stereotypes to the climate concerned was uniquely associated with pro-climate activism, while in contrast, no other types of impressions about the climate concerned uniquely predicted interest in engaging in pro-climate activism. This suggests that ascription of agency and respect (i.e., positive masculine impressions) toward the climate concerned was associated with pro-climate activism more so than was nurturance and warmth (i.e., positive feminine impressions). Yet, ascription of masculine impressions to the climate concerned did not uniformly predict interest in engaging in pro-climate activism. Rather, ascribing negative masculine impressions of the climate concerned (i.e., bad but bold) did not uniquely predict interest in engaging in pro-climate activism and instead uniquely predicted interest in engaging in anti-climate activism. Although competing hypotheses in the introduction did not allow us to make this prediction in advance, this finding is consistent with proposition that a perceived threat from an agentic source may prompt anti-climate activism. These findings further suggest that although the climate concerned might be encouraged to present themselves as masculine in order to 
TABLE 2 | Impressions of the climate concerned as predictors of pro-climate activism (Study 1).

\begin{tabular}{|c|c|c|c|}
\hline & \multicolumn{3}{|c|}{ Pro-climate activism } \\
\hline & $\begin{array}{c}\text { Base model } \\
(95 \% \mathrm{Cl})\end{array}$ & $\begin{array}{l}\text { Main effects } \\
(95 \% \mathrm{Cl})\end{array}$ & $\begin{array}{l}\text { Interactions } \\
\text { (95\% Cl) }\end{array}$ \\
\hline $\begin{array}{l}\text { Concern about climate } \\
\text { change (mean } \\
\text { centered) }\end{array}$ & $\begin{array}{c}0.90^{\star \star \star} \\
(0.74,1.07)\end{array}$ & $\begin{array}{c}0.73^{\star \star \star} \\
(0.55,0.92)\end{array}$ & $\begin{array}{c}0.73^{\star \star \star} \\
(0.55,0.91)\end{array}$ \\
\hline Political conservatism & $\begin{array}{l}-0.34^{\star \star \star} \\
(-0.54 \\
-0.14)\end{array}$ & $\begin{array}{l}-0.30^{\star \star} \\
(-0.50 \\
-0.10)\end{array}$ & $\begin{array}{l}-0.29^{\star \star} \\
(-0.49 \\
-0.09)\end{array}$ \\
\hline Anti-climate activism & $\begin{array}{c}0.45^{\star \star \star} \\
(0.28,0.62)\end{array}$ & $\begin{array}{c}0.44^{\star \star \star} \\
(0.27,0.61)\end{array}$ & $\begin{array}{c}0.43^{\star \star \star} \\
(0.26,0.60)\end{array}$ \\
\hline Participant gender & $\begin{array}{c}-0.14 \\
(-0.49,0.21)\end{array}$ & $\begin{array}{c}-0.26 \\
(-0.60,0.09)\end{array}$ & $\begin{array}{c}-0.23 \\
(-1.41,0.94)\end{array}$ \\
\hline Negative masculine & & $\begin{array}{c}-0.08 \\
(-0.36,0.20)\end{array}$ & $\begin{array}{c}-0.04 \\
(-0.40,0.32)\end{array}$ \\
\hline Negative feminine & & $\begin{array}{c}-0.16 \\
(-0.40,0.07)\end{array}$ & $\begin{array}{c}-0.14 \\
(-0.45,0.17)\end{array}$ \\
\hline Positive masculine & & $\begin{array}{c}0.27^{\star} \\
(0.03,0.52)\end{array}$ & $\begin{array}{c}0.14 \\
(-0.18,0.46)\end{array}$ \\
\hline Positive feminine & & $\begin{array}{c}0.08 \\
(-0.14,0.30)\end{array}$ & $\begin{array}{c}0.19 \\
(-0.12,0.50)\end{array}$ \\
\hline $\begin{array}{l}\text { Negative masculine } \\
\text { traits } \times \text { Gender }\end{array}$ & & & $\begin{array}{c}-0.10 \\
(-0.65,0.45)\end{array}$ \\
\hline $\begin{array}{l}\text { Negative feminine traits } \\
\times \text { Gender }\end{array}$ & & & $\begin{array}{c}-0.08 \\
(-0.56,0.40)\end{array}$ \\
\hline $\begin{array}{l}\text { Positive masculine } \\
\text { traits } \times \text { Gender }\end{array}$ & & & $\begin{array}{c}0.32 \\
(-0.17,0.80)\end{array}$ \\
\hline $\begin{array}{l}\text { Positive feminine traits } \\
\times \text { Gender }\end{array}$ & & & $\begin{array}{c}-0.22 \\
(-0.67,0.22)\end{array}$ \\
\hline Constant & $\begin{array}{c}0.05 \\
(-0.32,0.43)\end{array}$ & $\begin{array}{c}-0.24 \\
(-0.97,0.50)\end{array}$ & $\begin{array}{c}-0.31 \\
(-1.25,0.63)\end{array}$ \\
\hline Observations & 283 & 283 & 283 \\
\hline Log likelihood & -469.88 & -462.34 & -461.14 \\
\hline Wald test & $\begin{array}{c}190.63^{\star \star \star} \\
(\mathrm{df}=4)\end{array}$ & $\begin{array}{c}213.21^{\star \star \star} \\
(\mathrm{df}=8)\end{array}$ & $\begin{array}{l}217.03^{\star \star \star} \\
(\mathrm{df}=12)\end{array}$ \\
\hline
\end{tabular}

Values shown are unstandardized beta weights. 95\% Cl refers to the 95\% confidence interval. This table was created using stargazer (Hlavac, 2018). ${ }^{*} p<0.05 ;{ }^{* *} p<0.01$; ${ }^{* \star *} p<0.001$.

promote activism on climate change, they might be careful to avoid an appearance of the "dark side" of masculinity as this could exert an ironic anti-climate activist effect.

\section{STUDY 2: PERCEPTIONS OF THE CLIMATE DISMISSIVE}

The purpose of Study 2 was to examine whether individuals' impressions of the climate dismissive could explain interest in engaging in anti-climate (i.e., group consistent) and pro-climate (i.e., group inconsistent) activism.

\section{METHOD}

\section{Participants}

Two hundred seventy-two participants were recruited in February 2015 from MTURK (Mechanical Turk) and paid \$0.50 for their completion of the survey. Twenty-seven participants
TABLE 3 | Impressions of the climate concerned as predictors of anti-climate activism (Study 1).

\begin{tabular}{|c|c|c|c|}
\hline & \multicolumn{3}{|c|}{ Anti-climate activism } \\
\hline & $\begin{array}{l}\text { Base model } \\
(95 \% \mathrm{Cl})\end{array}$ & $\begin{array}{l}\text { Main effects } \\
(95 \% \mathrm{Cl})\end{array}$ & $\begin{array}{c}\text { Interactions } \\
(95 \% \mathrm{Cl})\end{array}$ \\
\hline $\begin{array}{l}\text { Concern about climate } \\
\text { change (mean } \\
\text { centered) }\end{array}$ & $\begin{array}{l}-0.47^{\star \star \star} \\
(-0.61 \\
-0.32)\end{array}$ & $\begin{array}{l}-0.38^{\star \star \star} \\
(-0.54 \\
-0.23)\end{array}$ & $\begin{array}{l}-0.38^{\star \star \star} \\
(-0.53 \\
-0.23)\end{array}$ \\
\hline Political conservatism & $\begin{array}{c}0.20^{*} \\
(0.03,0.37)\end{array}$ & $\begin{array}{c}0.15 \\
(-0.02,0.32)\end{array}$ & $\begin{array}{c}0.16 \\
(-0.01,0.33)\end{array}$ \\
\hline Pro-climate activism & $\begin{array}{c}0.30^{\star \star \star} \\
(0.19,0.40)\end{array}$ & $\begin{array}{c}0.30^{\star \star \star} \\
(0.19,0.41)\end{array}$ & $\begin{array}{c}0.29^{\star \star \star} \\
(0.18,0.40)\end{array}$ \\
\hline Participant gender & $\begin{array}{c}-0.13 \\
(-0.41,0.16)\end{array}$ & $\begin{array}{c}-0.09 \\
(-0.37,0.20)\end{array}$ & $\begin{array}{c}0.45 \\
(-0.53,1.44)\end{array}$ \\
\hline Negative masculine & & $\begin{array}{c}0.31^{\star \star} \\
(0.09,0.54)\end{array}$ & $\begin{array}{c}0.40^{\star \star} \\
(0.11,0.69)\end{array}$ \\
\hline Negative feminine & & $\begin{array}{c}-0.01 \\
(-0.21,0.19)\end{array}$ & $\begin{array}{c}-0.003 \\
(-0.26,0.25)\end{array}$ \\
\hline Positive masculine & & $\begin{array}{c}0.003 \\
(-0.20,0.21)\end{array}$ & $\begin{array}{c}-0.003 \\
(-0.27,0.26)\end{array}$ \\
\hline Positive feminine & & $\begin{array}{c}0.07 \\
(-0.12,0.26)\end{array}$ & $\begin{array}{c}0.14 \\
(-0.12,0.40)\end{array}$ \\
\hline $\begin{array}{l}\text { Negative masculine } \\
\text { traits } \times \text { Gender }\end{array}$ & & & $\begin{array}{c}-0.22 \\
(-0.67,0.22)\end{array}$ \\
\hline $\begin{array}{l}\text { Negative feminine traits } \\
\times \text { Gender }\end{array}$ & & & $\begin{array}{c}-0.01 \\
(-0.40,0.38)\end{array}$ \\
\hline $\begin{array}{l}\text { Positive masculine } \\
\text { traits } \times \text { Gender }\end{array}$ & & & $\begin{array}{c}0.04 \\
(-0.36,0.45)\end{array}$ \\
\hline $\begin{array}{l}\text { Positive feminine traits } \\
\times \text { Gender }\end{array}$ & & & $\begin{array}{c}-0.14 \\
(-0.51,0.23)\end{array}$ \\
\hline Constant & $\begin{array}{l}-1.68^{\star \star \star} \\
(-1.89 \\
-1.48)\end{array}$ & $\begin{array}{l}-2.34^{\star \star \star} \\
(-2.87 \\
-1.82)\end{array}$ & $\begin{array}{l}-2.63^{\star \star \star} \\
(-3.34 \\
-1.93)\end{array}$ \\
\hline Observations & 283 & 283 & 283 \\
\hline Log likelihood & -407.85 & -400.88 & -399.68 \\
\hline Wald Test & $\begin{array}{l}66.16^{\star \star \star} \\
(d f=4)\end{array}$ & $\begin{array}{l}81.77^{\star \star \star} \\
(\mathrm{df}=8)\end{array}$ & $\begin{array}{l}84.88^{\star \star \star} \\
(d f=12)\end{array}$ \\
\hline
\end{tabular}

Values shown are unstandardized beta weights. 95\% Cl refers to the 95\% confidence interval. This table was created using stargazer (Hlavac, 2018). ${ }^{*} p<0.05 ;{ }^{* *} p<0.01$; ${ }^{\star \star *} p<0.001$.

were excluded for failing an instructional check (7), completing in $<1 / 2$ the median completion time (17), and/or completing in $>3 \times$ the median completion time (7). The final sample consisted of 245 participants: 146 (60\%) women and 99 (49\%) men. Ages ranged from 19 to 78 (median =33). Most participants were White/Caucasian (81\%). The sample was somewhat more educated than the general public: $39 \%$ of participants had a 4-years college degree. About half of participants identified as politically liberal (10\% very liberal and 32\% liberal), followed by moderate $(35 \%)$ and about one-fifth as politically conservative ( $18 \%$ conservative, $5 \%$ very conservative). Like Study 1 and the general public (Maibach et al., 2011; Leiserowitz et al., 2015; Swim and Geiger, 2017), more participants were concerned than unconcerned about climate change: $26 \%$ self-identified as Alarmed, $39 \%$ as Concerned, $17 \%$ as Cautious, $4 \%$ as Disengaged, $7 \%$ as Doubtful, and $7 \%$ as Dismissive. 
TABLE 4 | Means, standard deviations, and correlations with confidence intervals for measures used in Study 2.

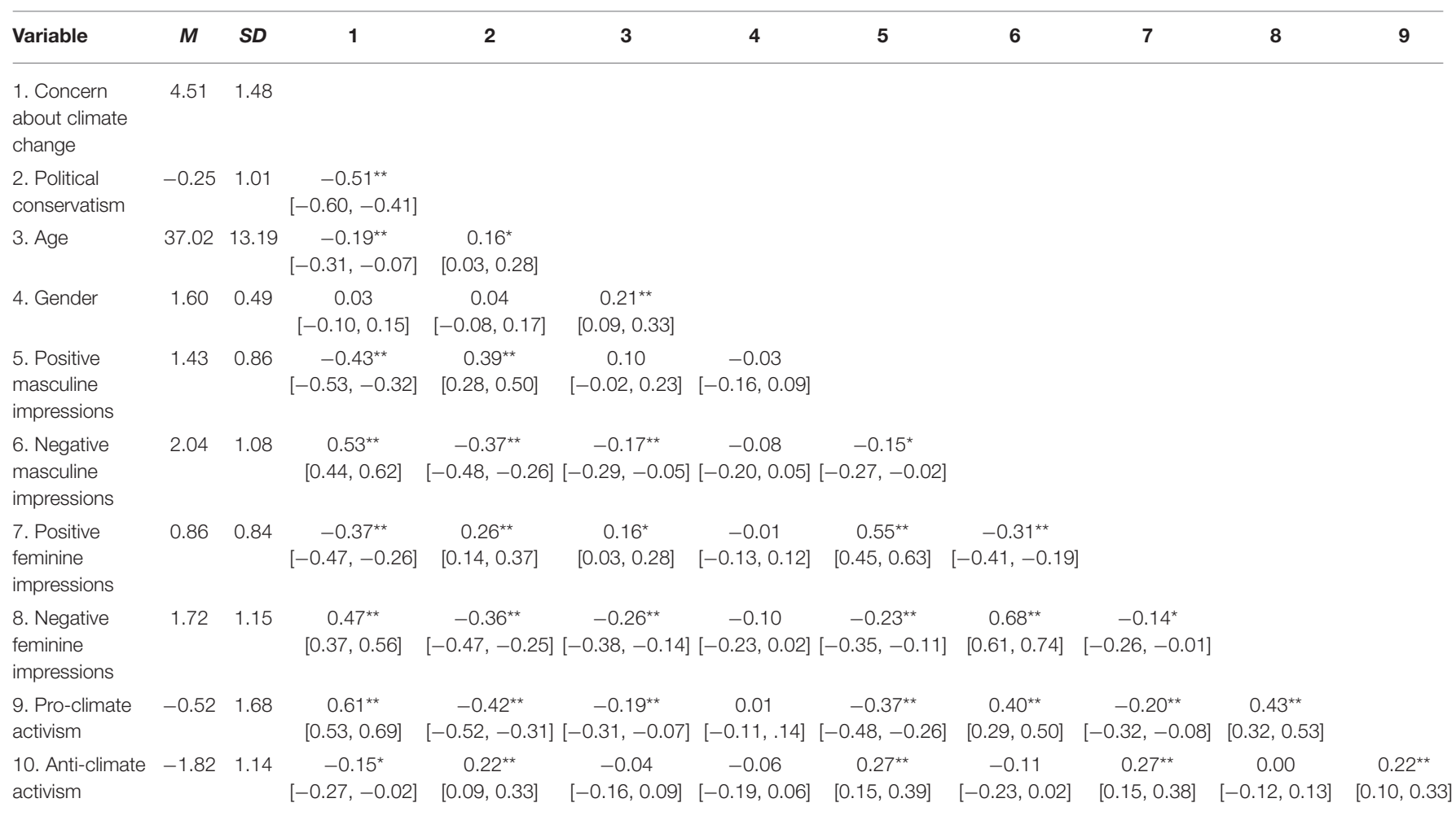

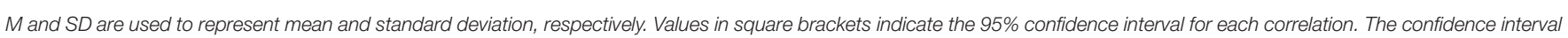
is a plausible range of population correlations that could have caused the sample correlation (Cumming, 2014). ${ }^{*}$ indicates $p<0.05$. ${ }^{\star *}$ indicates $p<0.01$.

\section{Procedure, Materials, and Measures}

The procedure was identical to that from Study 1 except that participants read quotes that were dismissive of climate change and the provided trait ratings of the Dismissive (see Appendix). The trait ratings were the same as those used in Study 1 (positive masculine traits, Cronbach $\alpha=0.69$; negative masculine traits: Cronbach $\alpha=0.83$; positive feminine traits, Cronbach $\alpha=$ 0.86; negative feminine traits, Cronbach $\alpha=0.86$ ) Again, model comparison supported a four-factor structure for trait ratings over two-factor and single-factor structures. Last, using the same items in Study 1, participants indicated their interest in engaging in pro-climate activism $(M=-0.52$, s.d. $=1,68, \alpha=0.81)$ and anti-climate activism $(M=-1.82, s . d .=1.14, \alpha=0.68)$. As before, we used Tobit regression due to floor effects on outcome measures. ${ }^{4}$

\section{RESULTS}

A table of zero-order correlations between all predictors and outcomes is shown in Table 4.

As in Study 1, we conducted regression analyses to examine the predictors of activism consistent with the issue public group

\footnotetext{
${ }^{4}$ Similar to Study 1, we assessed participants' identification with the climate dismissive for exploratory purposes. As in Study 1, there were no significant interactions between this measure and trait ascriptions on activism at the $p=0.05$ level.
}

being studied (i.e., anti-climate activism) and predictors of activism inconsistent with the issue public group being studied (i.e., pro-climate activism). As before, with each of these two outcome variables, we began by regressing the outcome measure upon political ideology, climate change concern, the opposite form of activism and gender in Step 1. In Step 2, we added in main effects of the four types of trait impressions. In Step 3, interactions between each of the types of trait impressions and gender were added. Below, we describe results in the text related to a) testing specific hypotheses and $b$ ) statistically significant effects that were not hypothesized. For the full results, see Tables 5, 6.

\section{Gender Role Congruity Predictions}

Consistent with Hypothesis 2, there was an interaction between participants' own gender and perceptions of negative feminine traits of the climate dismissive on anti-climate activism, $b=$ 0.52 ( $\beta=0.26$ ), $S E=0.19, p=0.006$. As shown in Figure 1, higher levels of perceived negative feminine traits toward the climate dismissive (i.e., one standard deviation above the mean) were associated with women being more interested than men in engaging in anti-climate activism $(p<0.05)$, whereas the reverse pattern was identified among those who perceived low levels of negative feminine traits (i.e., one standard deviation below the mean) toward the climate dismissive ( $p>0.05)$. In addition, there was also an interaction between perceptions of positive feminine traits in the climate dismissive and participants' own gender on interest in engaging in anti-climate activism, $b=-0.53$ ( $\beta=$ 
$-0.19), S E=0.23, p=0.02$, but in this case the interaction was in the opposite direction from predictions derived from gender role congruency theory (i.e., Hypothesis 2). As shown in Figure 2, among those who perceived the climate dismissive to possess high levels of positive feminine traits (i.e., one standard deviation above the sample mean), men were more interested in engaging in anti-climate activism than women $(p<0.05)$. In contrast, among those who perceived the climate dismissive to possess low levels of positive feminine traits (i.e., one standard deviation below the sample mean), women were equally interested as men at engaging in anti-climate activism $(p>0.05)$.

In contrast, Hypothesis 1 was not supported-there was no interaction between participants own gender and perceptions of either (a) positive or (b) negative masculine traits on interest in engaging in anti-climate activism, $p$ s $>0.05$.

\section{General Effects of Gendered Trait Impressions}

Similar to Study 1 findings, ascribing positive masculine traits to the climate dismissive predicted interest in engaging in anticlimate activism (Hypothesis $3 a), b=0.49(\beta=0.37), S E=0.12, p$ $<0.001$. In contrast, and also consistent with patterns in Study 1 , Hypothesis 4a was not supported: ascription of negative feminine traits of the climate dismissive did not uniquely predict interest in engaging in anti-climate activism, $b=0.13(\beta=0.14), S E=$ $0.10, p=17$. However, we did find a unique negative relation between negative masculine impressions of the climate dismissive and interest in engaging in anti-climate action, $b=-0.24(\beta=$ $-0.23), S E=0.11, p=0.026$.

Results supported Hypothesis 3b: pro-climate activism was uniquely predicted by ascribing less positive masculine impressions of the climate dismissive, $b=-0.42(\beta=-0.30), S E$ $=0.12, p<0.001$. In contrast, Hypothesis $4 \mathrm{~b}$ was not supported: pro-climate activism was not uniquely predicted by negative feminine impressions of the climate dismissive, $b=0.06$ ( $\beta=$ $0.04), S E=0.10, p=0.55$. However, we did find a positive unique relation between negative masculine impressions of the climate dismissive and interest in engaging in pro-climate action, $b=$ $0.24(\beta=0.15), S E=0.12, p=0.042$.

\section{DISCUSSION}

Unlike in Study 1, in Study 2 we did identify some interactions between gendered trait impressions and participants' own gender on interest in engaging in activism. Yet, the pattern of interactions was not entirely consistent with the predictions made by gender role theory. Supporting gender role consistency theory (Hypothesis 2), participants' gender interacted with negative feminine impressions of the climate dismissive in the expected direction to predict anti-climate activism: men were less interested than women in engaging in anti-climate activism among participants who viewed the climate dismissive to have negative feminine traits. Yet, the interaction between positive feminine traits and participants' gender on anti-climate activism was in the opposite direction and directly opposed predictions (Hypothesis 2): men were more interested than
TABLE 5 | Impressions of the climate dismissive as predictors of anti-climate activism (Study 2).

\begin{tabular}{|c|c|c|c|}
\hline & \multicolumn{3}{|c|}{ Anti-climate activism } \\
\hline & $\begin{array}{l}\text { Base model } \\
(95 \% \mathrm{Cl})\end{array}$ & $\begin{array}{l}\text { Main effects } \\
(95 \% \mathrm{Cl})\end{array}$ & $\begin{array}{c}\text { Interactions } \\
(95 \% \mathrm{Cl})\end{array}$ \\
\hline $\begin{array}{l}\text { Concern about climate } \\
\text { change (mean } \\
\text { centered) }\end{array}$ & $\begin{array}{l}-0.33^{\star \star \star} \\
(-0.48 \\
-0.19)\end{array}$ & $\begin{array}{l}-0.21^{\star *} \\
(-0.36 \\
-0.06)\end{array}$ & $\begin{array}{l}-0.18^{\star} \\
(-0.33 \\
-0.03)\end{array}$ \\
\hline Political Conservatism & $\begin{array}{c}0.37^{\star \star \star} \\
(0.18,0.55)\end{array}$ & $\begin{array}{c}0.25^{\star \star} \\
(0.07,0.43)\end{array}$ & $\begin{array}{c}0.23^{\star} \\
(0.05,0.40)\end{array}$ \\
\hline Pro-Climate Activism & $\begin{array}{c}0.49^{\star \star \star} \\
(0.37,0.62)\end{array}$ & $\begin{array}{c}0.52^{\star \star \star} \\
(0.40,0.65)\end{array}$ & $\begin{array}{c}0.49^{\star \star \star}(0.37 \\
0.62)\end{array}$ \\
\hline Participant Gender & $\begin{array}{c}-0.19 \\
(-0.52,0.13)\end{array}$ & $\begin{array}{c}-0.17 \\
(-0.47,0.13)\end{array}$ & $\begin{array}{c}-0.50 \\
(-1.44,0.44)\end{array}$ \\
\hline Negative Masculine & & $\begin{array}{l}-0.24^{\star} \\
(-0.46 \\
-0.03)\end{array}$ & $\begin{array}{c}-0.10 \\
(-0.42,0.21)\end{array}$ \\
\hline Negative Feminine & & $\begin{array}{c}0.13 \\
(-0.06,0.33)\end{array}$ & $\begin{array}{c}-0.16 \\
(-0.45,0.12)\end{array}$ \\
\hline Positive Masculine & & $\begin{array}{c}0.49^{\star \star \star} \\
(0.25,0.72)\end{array}$ & $\begin{array}{c}0.32 \\
(-0.004 \\
0.64)\end{array}$ \\
\hline Positive Feminine & & $\begin{array}{c}0.09 \\
(-0.14,0.32)\end{array}$ & $\begin{array}{c}0.40^{*} \\
(0.06,0.74)\end{array}$ \\
\hline $\begin{array}{l}\text { Negative masculine } \\
\text { traits } \times \text { Gender }\end{array}$ & & & $\begin{array}{c}-0.29 \\
(-0.70,0.11)\end{array}$ \\
\hline $\begin{array}{l}\text { Negative feminine traits } \\
\times \text { Gender }\end{array}$ & & & $\begin{array}{c}0.52^{\star \star} \\
(0.15,0.90)\end{array}$ \\
\hline $\begin{array}{l}\text { Positive masculine } \\
\text { traits } \times \text { Gender }\end{array}$ & & & $\begin{array}{c}0.33 \\
(-0.10,0.76)\end{array}$ \\
\hline $\begin{array}{l}\text { Positive feminine traits } \\
\times \text { Gender }\end{array}$ & & & $\begin{array}{l}-0.53^{\star} \\
(-0.98 \\
-0.08)\end{array}$ \\
\hline Constant & $\begin{array}{l}-1.54^{\star \star \star} \\
(-1.80 \\
-1.27)\end{array}$ & $\begin{array}{l}-2.07^{\star \star \star} \\
(-2.59 \\
-1.55)\end{array}$ & $\begin{array}{l}-1.87^{\star \star \star} \\
(-2.63 \\
-1.12)\end{array}$ \\
\hline Observations & 240 & 240 & 240 \\
\hline Log Likelihood & -347.00 & -332.66 & -327.09 \\
\hline Wald Test & $\begin{array}{l}69.47^{\star \star \star} \\
(\mathrm{df}=4)\end{array}$ & $\begin{array}{l}104.67^{\star \star \star} \\
(\mathrm{df}=8)\end{array}$ & $\begin{array}{l}118.76^{\star \star \star} \\
(\mathrm{df}=12)\end{array}$ \\
\hline
\end{tabular}

Values shown are unstandardized beta weights. $95 \% \mathrm{Cl}$ refers to the $95 \%$ confidence interval. This table was created using stargazer (Hlavac, 2018). ${ }^{*} p<0.05$; ${ }^{* *} p<0.01$; ${ }^{* * *} p<0.001$.

women in engaging in anti-climate activism among participants who viewed the climate dismissive to have positive feminine traits. Because this pattern was not found in Study 1, and no other interactions between trait impressions and participants' own gender on either anti-climate or pro-climate activism were found here in Study 2, we are hesitant to conclude that theoretically driven predictions of gender matching preferences can be used to explain the results. Yet, these results suggest that at the very least, research which does not separate feminine impressions into positive and negative components should interpret findings consistent with gender role congruity theory cautiously because results could potentially differ based on how feminine impressions are operationalized.

Positive masculine stereotypes about the climate dismissive were the strongest predictor of pro-climate activism: the less 
TABLE 6 | Impressions of the climate dismissive as predictors of pro-climate activism (Study 2).

\begin{tabular}{|c|c|c|c|}
\hline & \multicolumn{3}{|c|}{ Pro-climate activism } \\
\hline & $\begin{array}{l}\text { Base model } \\
\text { (95\% Cl) }\end{array}$ & $\begin{array}{l}\text { Main effects } \\
(95 \% \mathrm{Cl})\end{array}$ & $\begin{array}{c}\text { Interactions } \\
\text { (95\% Cl) }\end{array}$ \\
\hline $\begin{array}{l}\text { Concern about climate } \\
\text { change (mean } \\
\text { centered) }\end{array}$ & $\begin{array}{c}0.75^{\star \star \star} \\
(0.62,0.89)\end{array}$ & $\begin{array}{c}0.60^{\star \star \star} \\
(0.45,0.75)\end{array}$ & $\begin{array}{c}0.60^{\star \star \star} \\
(0.45,0.75)\end{array}$ \\
\hline Political conservatism & $\begin{array}{l}-0.44^{\star \star \star} \\
(-0.64 \\
-0.24)\end{array}$ & $\begin{array}{l}-0.30^{\star \star} \\
(-0.49 \\
-0.11)\end{array}$ & $\begin{array}{l}-0.30^{\star \star} \\
(-0.50 \\
-0.11)\end{array}$ \\
\hline Anti-climate activism & $\begin{array}{c}0.61^{\star \star \star} \\
(0.46,0.77)\end{array}$ & $\begin{array}{c}0.66^{\star \star \star} \\
(0.50,0.81)\end{array}$ & $\begin{array}{c}0.64^{\star \star \star} \\
(0.48,0.80)\end{array}$ \\
\hline Participant gender & $\begin{array}{c}0.14(-0.21 \\
0.48)\end{array}$ & $\begin{array}{c}0.15 \\
(-0.18,0.48)\end{array}$ & $\begin{array}{c}-0.69 \\
(-1.71,0.33)\end{array}$ \\
\hline Negative masculine & & $\begin{array}{c}0.24^{*} \\
(0.01,0.47)\end{array}$ & $\begin{array}{c}0.02 \\
(-0.33,0.36)\end{array}$ \\
\hline Negative feminine & & $\begin{array}{c}0.06(-0.14 \\
0.26)\end{array}$ & $\begin{array}{c}0.08 \\
(-0.22,0.38)\end{array}$ \\
\hline Positive masculine & & $\begin{array}{l}-0.58^{\star \star \star} \\
(-0.84 \\
-0.32)\end{array}$ & $\begin{array}{l}-0.61^{\star \star \star} \\
(-0.96 \\
-0.26)\end{array}$ \\
\hline Positive feminine & & $\begin{array}{c}0.23 \\
(-0.02,0.48)\end{array}$ & $\begin{array}{c}0.17 \\
(-0.20,0.54)\end{array}$ \\
\hline $\begin{array}{l}\text { Negative masculine } \\
\text { traits } \times \text { Gender }\end{array}$ & & & $\begin{array}{c}0.36 \\
(-0.08,0.81)\end{array}$ \\
\hline $\begin{array}{l}\text { Negative feminine traits } \\
\times \text { Gender }\end{array}$ & & & $\begin{array}{c}-0.03 \\
(-0.44,0.38)\end{array}$ \\
\hline $\begin{array}{l}\text { Positive masculine } \\
\text { traits } \times \text { Gender }\end{array}$ & & & $\begin{array}{c}0.01 \\
(-0.47,0.49)\end{array}$ \\
\hline $\begin{array}{l}\text { Positive feminine traits } \\
\times \text { Gender }\end{array}$ & & & $\begin{array}{c}0.12 \\
(-0.38,0.63)\end{array}$ \\
\hline Constant & $\begin{array}{c}0.26(-0.11 \\
0.63)\end{array}$ & $\begin{array}{c}0.40 \\
(-0.23,1.04)\end{array}$ & $\begin{array}{c}0.91^{*} \\
(0.05,1.76)\end{array}$ \\
\hline Observations & 240 & 240 & 240 \\
\hline Log likelihood & -372.17 & -359.42 & -357.31 \\
\hline Wald Test & $\begin{array}{c}230.09^{\star \star \star} \\
(\mathrm{df}=4)\end{array}$ & $\begin{array}{c}270.84^{\star \star \star} \\
(\mathrm{df}=8)\end{array}$ & $\begin{array}{l}275.47^{\star \star \star} \\
(\mathrm{df}=12)\end{array}$ \\
\hline
\end{tabular}

Values shown are unstandardized beta weights. 95\% Cl refers to the $95 \%$ confidence interval. This table was created using stargazer (Hlavac, 2018). ${ }^{*} p<0.05 ;{ }^{* *} p<0.01$; ${ }^{\star \star \star} p<0.001$.

individuals ascribed positive masculine stereotypes to the climate dismissive, the more interest they reported in pro-climate activism. Aside from the interactions described in the paragraph above, primary conclusions from Study 2 are fairly similar to Study 1 and suggest that our predictions tend to replicate when the issue public group is varied from the climate concerned to the climate dismissive. Specifically, these results are consistent with the notion that perceiving the climate dismissive as possessing positive masculine traits (but not positive feminine traits) can not only encourage anti-climate activism but also dampen enthusiasm for pro-climate activism. However, in contrast, these results are also consistent with the notion that perceiving the climate dismissive as "bad but bold" can exert the exact opposite effects, promoting oppositional pro-climate activism and discouraging enthusiasm for anti-climate activism, perhaps based on the lack of likability or perceived misuse of power when these individuals are perceived as possessing negative masculine traits.

\section{GENERAL DISCUSSION}

The present study corroborates previous findings that stereotypes about activist groups is an important predictor of interest in engaging in actions consistent with a groups position (Bashir et al., 2013), while illustrating that assessing the gendered nature of stereotypes can add insights into toward understanding these relations. Specifically, the present research indicates that it is positive masculine stereotypes associated with a public issue group more than simply positive and not negative stereotypes that are the most strongly associated with interest in engaging in activism. Further, the association between activism supporting a certain position and positive masculine traits ascribed to issue publics who hold that position were found for both pro- and anti-climate activism. The study also points to the importance of masculine more than feminine impressions for both activism that is consistent with a public issues stance and that which is diametrically opposed to its position.

Masculine traits reflect agency and the present results are consistent with the notion that impressions derived from status and power associated with the group influence interest in engaging in behaviors consistent with a groups position. It is possible that masculine stereotypes indicate respect for the positions taken by the group (Wojciszke et al., 2009). The results suggest, however, that it is not just any type of masculine trait impressions of a group that predicts interest in engaging in group-consistent activism because negative masculine impressions, when they predicted interest in engaging in activism, predicted lower interest in engaging in group-consistent activism and greater interest in engaging in group-inconsistent activism. Negative masculine stereotypes suggest a potential misuse of power (Diekman and Eagly, 2000). Thus, the results suggest the possibility that oppositional activism could be spurred in part by viewing an issue public group as a threat. It is also consistent with the strategy of negative advertising in political campaigns suggesting that such strategies can be effective when it comes to promoting forms of activism and discouraging others.

In contrast, despite the fact that negative feminine stereotypes are as likely to be associated with the climate concerned as are positive masculine stereotypes (Swim and Geiger, 2018), in general these stereotypes do not appear to uniquely predict interest in engaging in either pro-climate or anti-climate activism. This suggests that neither warmth or lack of status can fully explain relations between these trait ratings and interest in engaging inactivist behaviors.

In contrast to the patterns of associations that were consistent with hypotheses based upon the social meaning suggested by gendered traits, our work did not find consistent evidence to support predictions derived gender role congruity theory. Specifically, we only identified one interaction that supported gender matching predictions derived from this theory: In Study 


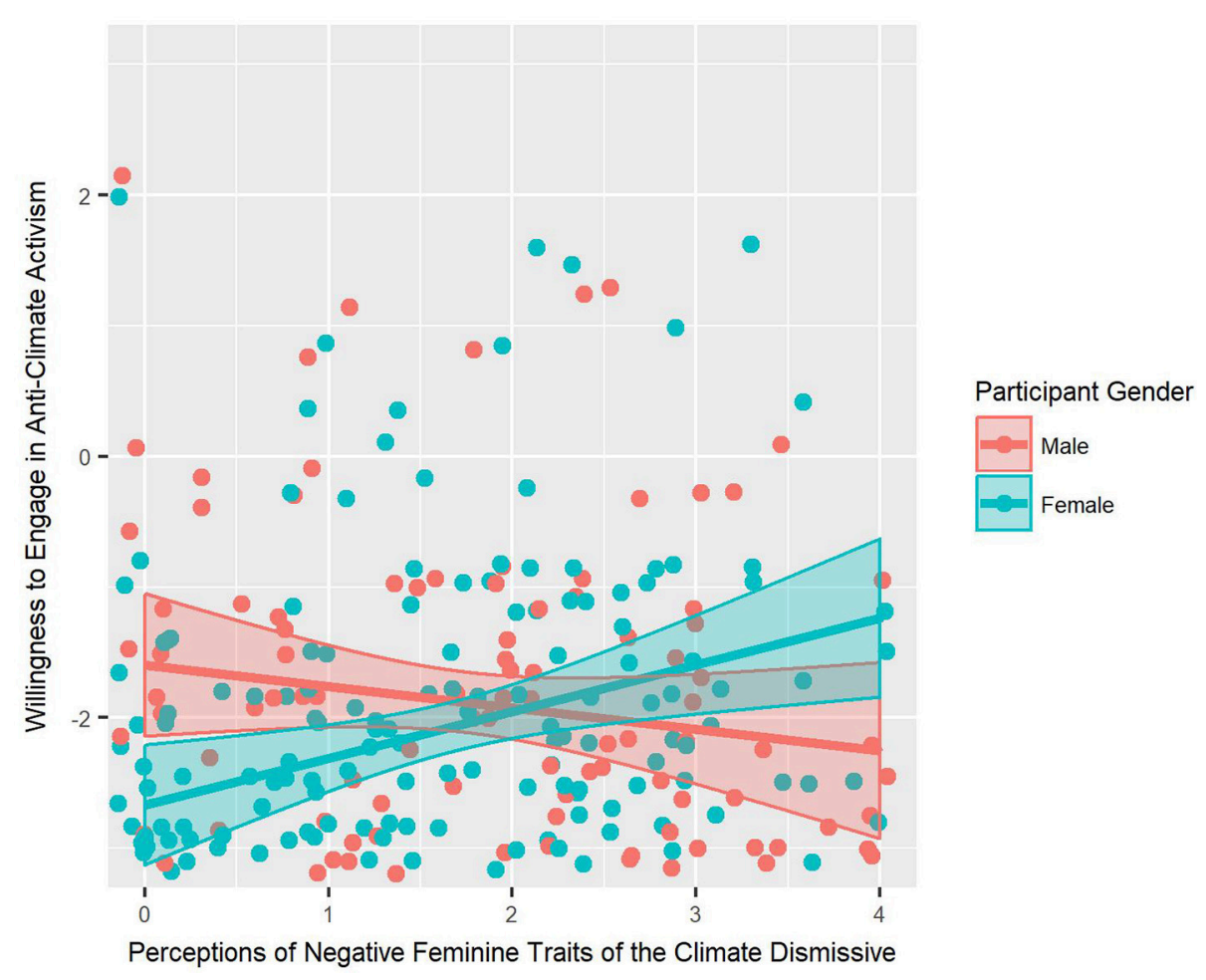

FIGURE 1 | Interactive effect of negative feminine trait perceptions of the climate dismissive and participants' own gender on interest in engaging in anti-climate activism (Study 2).

2 , men were reported less interest in than women in engaging in anti-climate activism when they perceived that the climate dismissive had negative feminine traits. Yet, this interaction was counterbalanced by the exact opposite patterns found with the same outcome measure and positive feminine traits: in this case, men appeared to be more drawn to those perceived to have positive feminine traits than women. Because this pattern was not consistently identified across other analyses or in Study 1, we cannot draw firm conclusions from these findings, but we suggest that future work consider the possibility that men's aversion to femininity in certain circumstances may stem from negative aspects of femininity (being whiny and complaining) rather than positive aspects of femininity (being caring and kind).

We have several speculations as to why we did not find support for gender role congruity theory. First, the lack of gender role congruity effect for women is potentially explained by the tendency for masculine traits to be generally valued. Thus, as has been argued by researchers studying masculinity and different impacts of gender identity threats on women and men, gender role congruity effects may not be as potent for women as it is for men (Swim et al., 2018). For men, it is possible that taking a strong stance on climate change, either opposing or supporting it, is sufficiently agentic to overcome a potential threat of appearing feminine. Or they may believe that the feminine qualities would not be associated with them because these qualities might be reserved for women activists (Swim, under review). Second, gender role congruity theory may have not been supported in this specific context because decisions about whether or not to participate in climate change activism are more strongly driven by other identities, such as political orientation or party, that gender concerns are not as relevant. Yet, this latter explanation cannot explain why gender role congruity theory was not supported here but social value of traits theory was supported.

\section{Limitations and Future Research}

There are limitations to the conclusions that can be drawn based on the study design. For one, the cross-sectional designs we employed in both studies do not allow us to conclusively establish causality. Thus, there may be other possibilities for the observed findings which are not consistent with the theoretical background we proposed. For example, it is possible that those who are already interested in engaging in activism may alter their impressions of activists rather than the other way around (or the process could be bi-directional). To better test our proposed model as compared to these alternative possibilities, future research could devise an experimental study in which perceptions of the climate concerned or climate dismissive are experimentally manipulated, or alternatively, devise a longitudinal cross-lagged study design which examines changes in individuals' perceptions of activists and interest in engaging in activism are examined at multiple timepoints during a life period. Additionally, future work could consider measuring actual activism behavior rather than interest in activism to verify that interest in activism translates into actual behavior. It is possible that some people may indicate interest in engaging in activism opposing an issue 


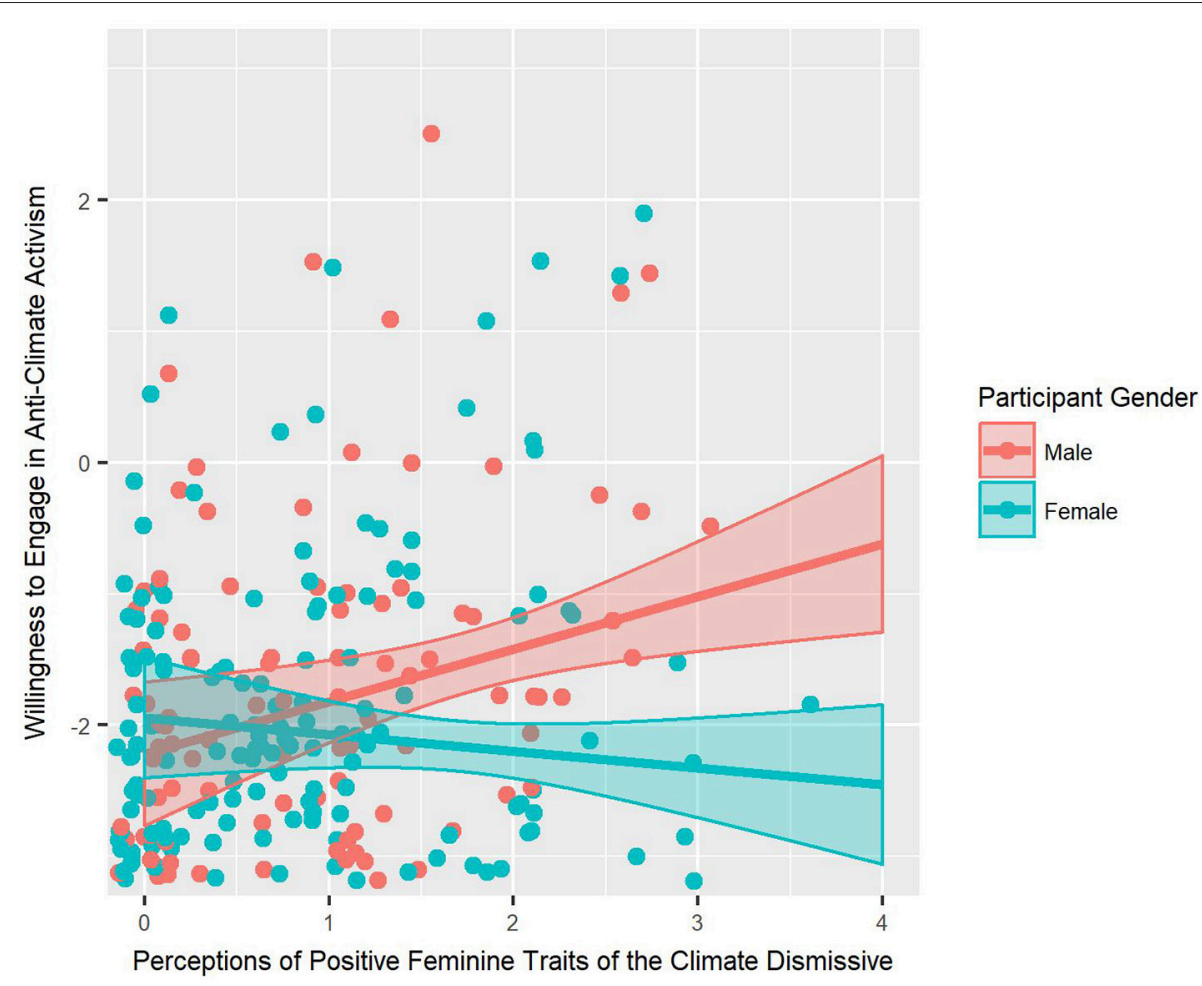

FIGURE 2 | Interactive effect of positive feminine trait perceptions of the climate dismissive and participants' own gender on interest in engaging in anti-climate activism (Study 2).

public's position but the public confrontational nature of the activism may dissuade them (Swim and Hyers, 1999).

Future work might also examine whether different framings of climate change could influence the extent to which gendered traits were ascribed to issue publics. For example, it is possible that use of "war" metaphors to describe climate change (Rao, 2015; McKibben, 2016) might lead people to ascribe masculine traits to climate change issue publics because war may be seen as a masculine venture.

Another direction for future research could be to test impressions of opinion groups on both sides of an issue as simultaneous predictors in the same study. Here, we tested them separately in Study 1 and Study 2. Yet, it is likely that perceptions of the climate alarmed are negatively correlated with perceptions of the climate dismissive. Including them both in the same model could improve our understanding of whether perceptions of the consistent issue public or the opposing issue public are better predictors of interest in engaging in activism.

Future work could also extend this work by considering a variety of political topics to examine whether the patterns identify in the present work replicate across different topics or whether they are specific to the topic of climate change. For example, it is possible that with regard to issues seen as "social issues" rather than "environmental issues" that the positive feminine traits may play a greater role since these traits are arguably related to caring about marginalized groups (a relevant consideration with regard to social issues), while people may not readily consider the justice implications associated with environmental issues such climate change (Swim and Bloodhart, 2018).

A final direction for future research could be to expand this research by considering the role that intergroup dynamics might play in the connections between perceptions of issue publics and interest in engaging in activist behavior. Although a discussion of intergroup relations and behavior is beyond the scope of the present work (but see footnotes 2 and 4 for exploratory analyses), recent work on the topic (Blatz and Mercier, 2018; Van Boven et al., 2018) suggests the potential for conceptual overlap between that work and the present theories. We suggest that future work might connect these two sets of literatures in the service of developing a model with more predictive power of who will ultimately engage in activist behaviors.

\section{CONCLUSION}

The present work builds upon an increasing trend among those using an intergroup perspective to understand social processes that influence climate change engagement (Bliuc et al., 2015; Pearson et al., 2016). Here, we illustrate the importance of considering the gendered nature of stereotypes that individuals have about social groups in predicting interest in engaging in activist behaviors. Our work suggests that masculine stereotypes about groups may be particularly relevant for understanding engagement in activism and that research can be best served by empirically separating positive and negative components of 
masculinity when evaluating individuals' impressions of others. It is our hope this framework and these findings open up new considerations and possibilities for those interesting in understanding the complexities of how individuals come to engage in activism.

\section{ETHICS STATEMENT}

This study was carried out in accordance with the recommendations of name of guidelines, name of committee with written informed consent from all subjects. All subjects gave written informed consent in accordance with the Declaration of Helsinki. The protocol was approved by the Institutional Review Board at the Pennsylvania State University.

\section{REFERENCES}

Abele, A. E., and Wojciszke, B. (2007). Agency and communion from the perspective of self versus others. J. Pers. Soc. Psychol. 93, 751-763. doi: 10.1037/0022-3514.93.5.751

Barker, D. (2016). Ten Years Later, Al Gore's "Inconvenient Truth" Propaganda Film Turns Out to be Total Bunk... How is his Profit From Carbon Taxes not Criminal FRAUD? - NaturalNews.com. Available online at: https://www. naturalnews.com/053992_Inconvenient_Truth_climate_change_hoax_Al Gore_fraud.html (Retrieved August 2, 2018).

Bashir, N. Y., Lockwood, P., Chasteen, A. L., Nadolny, D., and Noyes, I. (2013). The ironic impact of activists: negative stereotypes reduce social change influence. Eur. J. Soc. Psychol. 43, 614-626. doi: 10.1002/ejsp.1983

Blatz, C. W., and Mercier, B. (2018). False polarization and false moderation: political opponents overestimate the extremity of each other's ideologies but underestimate each other's certainty. Soc. Psychol. Pers. Sci. 9, 521-529. doi: 10.1177/1948550617712034

Bliuc, A.-M., McGarty, C., Thomas, E. F., Lala, G., Berndsen, M., and Misajon, R. (2015). Public division about climate change rooted in conflicting sociopolitical identities. Nat. Clim. Change 5, 226-229. doi: 10.1038/nclimate2507

Böhm, R., Rusch, H., and Gürerk, Ö. (2016). What makes people go to war? Defensive intentions motivate retaliatory and preemptive intergroup aggression. Evol. Hum. Behav. 37, 29-34. doi: 10.1016/j.evolhumbehav.2015.06.005

Breen, R. (1996). “The Tobit model for censored data," in Regression Models (Thousand Oaks, CA: SAGE Publications, Inc.), 12-33.

Brough, A. R., Wilkie, J. E. B., Ma, J., Isaac, M. S., and Gal, D. (2016). Is ecofriendly unmanly? The green-feminine stereotype and its effect on sustainable consumption. J. Consumer Res. 43, 567-582. doi: 10.1093/jcr/ucw044

Bump, P. (2013, August 20). Daily Caller Writer Deems Obama the "First Female President." Available online at: https://www.theatlantic.com/politics/archive/ 2013/08/obama-has-now-been-called-first-female-president-five-times/ 311953/ (Retrieved September 25, 2018).

Cottrell, C. A., and Neuberg, S. L. (2005). Different emotional reactions to different groups: a sociofunctional threat-based approach to "Prejudice." J. Pers. Soc. Psychol. 88, 770-789. doi: 10.1037/0022-3514.88.5.770

Cumming, G. (2014). The new statistics: why and how. Psychol sci. 25, 7-29. doi: 10.1177/0956797613504966

Deaux, K., and Lafrance, M. (1998). “Gender," in 4th Edn., eds D. T. Gilbert, S. T. Fiske, and G. Lindzey (New York, NY: McGraw-Hill), 788-827. Retrieved from: http://search.proquest.com/psycinfo/docview/619359876/abstract/ 3580E08D71584A5APQ/1

Diekman, A. B., and Eagly, A. H. (2000). Stereotypes as dynamic constructs: Women and men of the past, present, and future. Pers. Soc. Psychol. Bull. 26, 1171-1188. doi: 10.1177/0146167200262001

Diekman, A. B., and Eagly, A. H. (2008). "Of men, women, and motivation: a role congruity account," in Handbook of Motivation Science, eds J. Y. Shah and W. L. Gardner (New York, NY: Guilford Press), 434-447.

\section{AUTHOR CONTRIBUTIONS}

NG and JKS developed the study concept. Data collection was performed by JKS. NG performed the data analysis and interpretation under the supervision of JKS. NG drafted the manuscript, and JKS provided critical revisions. All authors approved the final version of the manuscript for submission.

\section{FUNDING}

This research was funded in part a grant by from the National Science Foundation (NSF-BCS \#1152147) awarded to JKS and Theresa K. Vescio.

Dineen, K. P. (2011). The Tea Party Movement, the Conservative Establishment, and the Collapse of Climate Change Legislation. Master's Thesis; Massachusetts Institute of Technology.

Eagly, A. H. (1987). Sex Differences in Social Behavior: A Social-Role Interpretation. Hillsdale, NJ: Lawrence Erlbaum Associates, Inc.

Eagly, A. H., and Steffen, V. J. (1984). Gender stereotypes stem from the distribution of women and men into social roles. J. Pers. Soc. Psychol. 46, 735-754. doi: 10.1037/0022-3514.46.4.735

Eagly, A. H., Wood, W., and Diekman, A. B. (2000). "Social role theory of sex differences and similarities: a current appraisal," in The Developmental Social Psychology of Gender (Mahwah, NJ: Lawrence Erlbaum Associates Publishers), 123-174.

Elmore, K. C., and Oyserman, D. (2012). If 'we'can succeed,'I'can too: Identitybased motivation and gender in the classroom. Contemp. Educ. Psychol. 37, 176-185. doi: 10.1016/j.cedpsych.2011.05.003

Geiger, N. (2018). How Policy Perceptions are Derived From Speaker Characteristics. University Park, PA: Penn State University.

Geiger, N., and Swim, J. K. (2016). Climate of silence: Pluralistic ignorance as a barrier to climate change discussion. J. Environ. Psychol. 47, 79-90. doi: 10.1016/j.jenvp.2016.05.002

Glick, P., Lameiras, M., Fiske, S. T., Eckes, T., Masser, B., Volpato, C., et al. (2004). Bad but bold: Ambivalent attitudes toward men predict gender inequality in 16 nations. J. Pers. Soc. Psychol. 86, 713-728. doi: 10.1037/0022-3514.86.5.713

Hlavac, M. (2018). Stargazer: Well-Formatted Regression and Summary Statistics Tables. R package version 5.2.2. Available online at: https://CRAN.Rproject.org/package $=$ stargazer

Hogg, M. A., Turner, J. C., and Davidson, B. (1990). Polarized norms and social frames of reference: a test of the self-categorization theory of group polarization. Basic Appl. Soc. Psychol. 11, 77-100. doi: 10.1207/s15324834basp1101_6

Klandermans, B. (2008). "The demand and supply of participation: socialpsychological correlates of participation in social movements," in The Blackwell Companion to Social Movements, eds D. A. Snow, S. A. Soule, and H. Kriesi (Malden, MA: John Wiley \& Sons), 360-379.

Klas, A., Zinkiewicz, L., Zhou, J., and Clarke, E. J. R. (2018). "Not All Environmentalists Are Like That ... ": unpacking the negative and positive beliefs and perceptions of environmentalists. Environ. Commun. 0, 1-15. doi: 10.1080/17524032.2018.1488755

Lau, R. R., Sigelman, L., Heldman, C., and Babbitt, P. (1999). The effects of negative political advertisements: a meta-analytic assessment. Am. Polit. Sci. Rev. 93, 851-875

Leiserowitz, A., Maibach, E. W., Roser-Renouf, C., Feinberg, G., and Rosenthal, S. (2015). Climate Change in the American mind: March, 2015. New Haven, CT: Yale Project on Climate Change Communication: Yale University and George Mason University. Retrieved from: http://environment.yale.edu/ climate-communication/files/Global-Warming-CCAM-March-2015.pdf

London, B., Rosenthal, L., Levy, S. R., and Lobel, M. (2011). The influences of perceived identity compatibility and social support on women in nontraditional 
fields during the college transition. Basic Appl. Soc. Psychol. 33, 304-321. doi: 10.1080/01973533.2011.614166

Maibach, E. W., Leiserowitz, A., Roser-Renouf, C., and Mertz, C. K. (2011). Identifying like-minded audiences for global warming public engagement campaigns: an audience segmentation analysis and tool development. PLoS ONE 6:e17571. doi: 10.1371/journal.pone.0017571

Masson, T., and Fritsche, I. (2014). Adherence to climate change-related ingroup norms: do dimensions of group identification matter? Adherence to climate change-related ingroup norms. Eur. J. Soc. Psychol. 44, 455-465. doi: $10.1002 /$ ejsp. 2036

McAdam, D. (2017). Social movement theory and the prospects for climate change activism in the United States. Annu. Rev. Polit. Sci. 20, 189-208. doi: 10.1146/annurev-polisci-052615-025801

McCarter, J. (2014). Yes, The Koch Brothers Really Are That Evil. Available online at: https://www.dailykos.com/story/2014/10/8/1335246/-Yes-the-Kochbrothers-really-are-that-nbsp-evil (Retrieved August 4, 2018).

McKibben, B. (2016). A World at War. The New Republic. Retrieved from: https:// newrepublic.com/article/135684/declare-war-climate-change-mobilize-wwii

Miron, A. M., and Brehm, J. W. (2006). Reactance theory-40 years later. Zeitschr. Sozialpsychol. 37, 9-18. doi: 10.1024/0044-3514. 37.1.9

Mohai, P. (1992). Men, women, and the environment: an examination of the gender gap in environmental concern and activism. Soc. Nat. Resour. 5, 1-19. doi: $10.1080 / 08941929209380772$

Moyer, B. (1987). The Movement Action Plan: A Strategic Framework Describing the Eight Stages of Successful Social Movements. Available online at: http://www. historyisaweapon.com/defcon1/moyermap.html

Mufson, S., and Agiesta, J. (2009, June 25). Majority of Poll Respondents Say U.S. Should Limit Greenhouse Gases. Retrieved from: http://www.washingtonpost. com/wp-dyn/content/article/2009/06/24/AR2009062403648.html

Pearson, A. R., Schuldt, J. P., and Romero-Canyas, R. (2016). Social climate science: a new vista for psychological science. Persp. Psychol. Sci. 11, 632-650. doi: $10.1177 / 1745691616639726$

Polman, D. (2018, July 18). Can the GOP Demonize Pelosi One More Time? Available online at: https://www.theatlantic.com/politics/archive/2018/ 07/can-the-gop-demonize-pelosi-one-more-time/565466/ (Retrieved August 2, 2018).

Pryor, J. B., Reeder, G. D., and Monroe, A. E. (2012). The infection of bad company: stigma by association. J. Pers. Soc. Psychol. 102, 224-241. doi: 10.1037/a00 26270

Rao, V. (2015, October 15). Why Solving Climate Change Will Be Like Mobilizing for War. The Atlantic. Retrieved from: http://www.theatlantic.com/science/ archive/2015/10/why-only-a-technocratic-revolution-can-win-the-climatechange-war/410377/?utm_source=SFFB

Rome, A. (2006). "Political Hermaphrodites": gender and environmental reform in progressive America. Environ. Hist. 11, 440-463. doi: 10.1093/envhis/11.3.440

Spence, J. T., and Helmreich, R. L. (1979). Masculinity and Femininity: Their Psychological Dimensions, Correlates, and Antecedents. Austin, TX: University of Texas Press.
Stangor, C., Lynch, L., Duan, C., and Glas, B. (1992). Categorization of individuals on the basis of multiple social features. J. Pers. Soc. Psychol. 62, 207-218. doi: 10.1037/0022-3514.62.2.207

Swim, J. K., and Bloodhart, B. (2018). The intergroup foundations of climate change justice. Group Process. Intergr. Relat. 21, 472-496. doi: $10.1177 / 1368430217745366$

Swim, J. K., Fraser, J., and Geiger, N. (2014). Teaching the choir to sing: use of social science information to promote public discourse on climate change. $J$. Land Use Environ. Law 30:91. Retrieved from: http://heinonlinebackup.com/ hol-cgi-bin/get_pdf.cgi?handle=hein.journals/jluenvl30\&section $=10$

Swim, J. K., and Geiger, N. (2017). From alarmed to dismissive of climate change: a single item assessment of individual differences in concern and issue involvement. Environ. Commun. 11, 568-586. doi: $10.1080 / 17524032.2017 .1308409$

Swim, J. K., and Geiger, N. (2018). The gendered nature of stereotypes about climate change opinion groups. Group Process. Intergr. Relat. 21, 436-456. doi: $10.1177 / 1368430217747406$

Swim, J. K., and Hyers, L. L. (1999). Excuse me-what did you just say?!: Women's public and private responses to sexist remarks. J. Exp. Soc. Psychol. 35, 68-88. doi: 10.1006/jesp.1998.1370

Swim, J. K., Vescio, T. K., Dahl, J. L., and Zawadzki, S. J. (2018). Gendered discourse about climate change policies. Global Environ. Change 48, 216-225. doi: 10.1016/j.gloenvcha.2017.12.005

Tobin, J. (1958). Estimation of relationships for limited dependent variables. Econometrica 26, 24-36.

Van Boven, L., Ehret, P. J., and Sherman, D. K. (2018). Psychological barriers to bipartisan public support for climate policy. Persp. Psychol. Sci. 13, 492-507. doi: $10.1177 / 1745691617748966$

Wojciszke, B., Abele, A. E., and Baryla, W. (2009). Two dimensions of interpersonal attitudes: liking depends on communion, respect depends on agency. Eur. J. Soc. Psychol. 39, 973-990. doi: 10.1002/ejsp.595

Zelezny, L. C., Chua, P.-P., and Aldrich, C. (2000). New ways of thinking about environmentalism: elaborating on gender differences in environmentalism. J. Soc. Issues 56, 443-457. doi: 10.1111/0022-4537.00177

Zhu, L., and Gonzalez, J. (2017). Modeling floor effects in standardized vocabulary test scores in a sample of low SES Hispanic preschool children under the multilevel structural equation modeling framework. Front. Psychol. 8:2146. doi: $10.3389 /$ fpsyg.2017.02146

Conflict of Interest Statement: The authors declare that the research was conducted in the absence of any commercial or financial relationships that could be construed as a potential conflict of interest.

Copyright () 2018 Geiger and Swim. This is an open-access article distributed under the terms of the Creative Commons Attribution License (CC BY). The use, distribution or reproduction in other forums is permitted, provided the original author(s) and the copyright owner(s) are credited and that the original publication in this journal is cited, in accordance with accepted academic practice. No use, distribution or reproduction is permitted which does not comply with these terms. 


\section{APPENDIX}

Study 1 participants read the following four quotes, which were obtained from open-ended responses collected from participants in a different study: (1) "Climate change is a topic that needs to be addressed. Nobody seems too concerned about it and by the time people really want to do something about it, it will be too late"; (2) "I find it unacceptable that those who did not even complete a science course in our tax-sponsored school system (some of who are now in government) claim to understand all about science, and presume to deny the findings of science while the rest of us continue to overheat"; (3) "While I agree that a lot of the proposals would negatively impact the economy, I believe that we need to do something about climate change, even if it's a small step, and that needs to be done now, not later. I favor an incremental approach, but that approach should start today"; (4) "Climate change is real, and it appears that policymakers are simply wringing their hands, refusing to find real solutions to problems. I think that at this point, any and all measures are helpful, both simple policies and far-reaching policies."
Study 2 participants read the following four quotes (which were also obtained from participants in another study): (1) "There is new support for the theory that radiation from sunspots are ultimately behind global warming-not man-made causes of carbon emissions. We're in a season of particularly high solar activity"; (2) "I remember when I was young that they were warning about the coming ice age. Al Gore's 2007 prediction that all arctic ice would be gone by 2014 is now proven to be alarming fear mongering. It's all about money and power"; (3) "Numerous scientists are admitting they falsified data. The agenda originally was global warming, now climate change. Antarctica has more sea ice now than in past decades. It is truly sad people blindly follow this hoax being played on them by academia, the media, and government"; and (4) "The climate is changing as it has been for millions of years. We are not going to be able to change that regardless of how much money we spend".

In both studies, the quotes were paired with either a) four male names (Philip, Robert, Andrew, David), b) four female names (Julie, Diedra, Emily, Isabella) or c) two female and two male names (Julie, Philip, Diedra, Andrew). 